\title{
Doctors should collaborate with traditional healers
}

A n Aboriginal doctor who testified in the case of a Mohawk girl whose family opted out of chemotherapy is urging physicians to work more collaboratively with traditional healers and to respect their practices.

"Traditional medicine is a system of medicine in the same way that Western medicine is a system, in the same way naturopathic medicine is a system," says Dr. Karen Hill, who shares a practice with traditional healer Elva Jamieson on the Six Nations of the Grand River First Nation in Ohsweken, Ont. "Because it doesn't look the same, I think physicians don't know how to receive it."

Hill, who is Mohawk, believes a clash of cultures influenced the decision of doctors at the McMaster Children's Hospital in Hamilton, Ont., to ask Judge Gethin Edward of the Ontario Court of Justice to compel cancer treatment for J.J, an 11-year-old Mohawk girl who has acute lymphoblastic leukemia. Although Hill neither confirmed nor denied that she and Jamieson are treating J.J., Hill did testify in the case. Edward ruled in November 2014 that J.J.'s mother, the girl's substitute decision-maker, had a constitutionally guaranteed right to practise traditional medicine.

On Jan. 19, 2015, Makayla Sault, another 11-year-old Aboriginal girl with leukemia, died following a stroke. Makayla and her family, who are from the neighbouring Mississaugas of the New Credit First Nation, had also stopped chemotherapy at McMaster. Makayla's death has drawn international attention to the issue of consent to treatment and whether Aboriginal rights may potentially clash with a child's best interests and right to life.

Both cases have also raised the question of how doctors should respond to an Aboriginal patient's desire to pursue traditional or other types of medicine over Western medical treatment. "The big message is that this is not just about medical choice," Hill told CMAJ. "This is about indigenous people

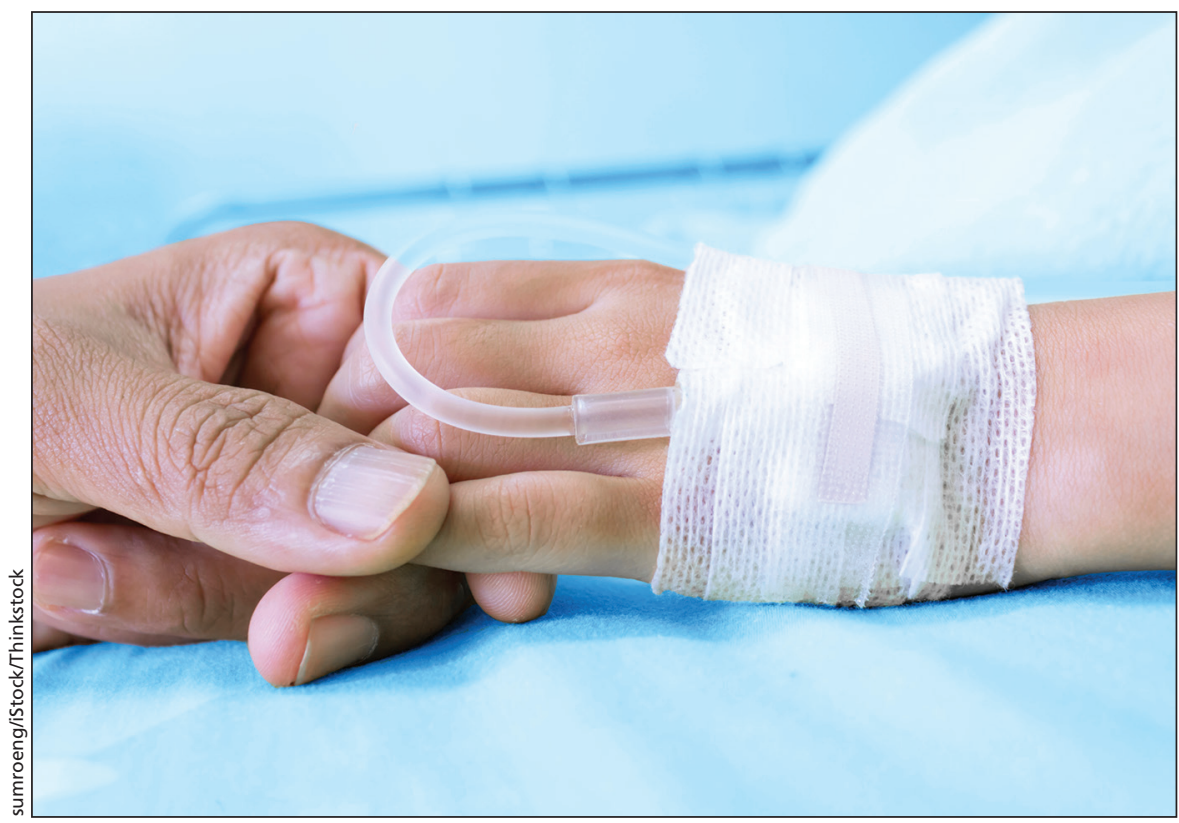

An Ontario court ruled that the substitute decision-maker for an 11-year-old Mohawk girl with acute lymphoblastic leukemia had a constitutionally guaranteed right to practise traditional medicine.

reclaiming their wholeness as people. This isn't about religion; it isn't about choice. It's about being who we are."

Choosing one type of treatment over the other is not the only option, say Hill and Dr. Veronica McKinney, a Cree/ Métis woman who is on the executive of the Indigenous Physicians Association of Canada.

"More and more people are coming to understand that you can have a blend (of treatments)," says McKinney, who is the director of Northern Medical Services at the University of Saskatchewan. "I have a number of patients where this is the case, and I support that."

Hill, who graduated from McMaster University medical school, and Jamieson, who apprenticed with her mother on Six Nations, often work together with patients to plan a combination of traditional and Western medical treatment.

In J.J.'s case, McMaster made an effort to permit the family to pursue its traditional practices, says Daphne Jarvis, McMaster's lawyer. "There was a ceremony that took place in the hospital that the family arranged and they seemed very appreciative of that," she told CMAJ. "With respect to the use of traditional medicines, I think the caveat was: 'as long as it doesn't interfere with the chemotherapy' - so that was perceived to be hierarchical, which it wasn't intended to be.'

Practitioners need a trusting relationship with their patients that includes selfreflection, respect for other world views, and reciprocity that acknowledges the patient's contribution to healing, says McKinney. "When you are the one making all the decisions aside from the patient, you're going off-track. It doesn't matter whether we're talking cancer or high blood pressure ... that completely does not match patient-centred care."

There are few medical institutions in Canada, McKinney says, that support the positive contributions of traditional medicine, which includes plant-based medicines, ritual and ceremonies, alongside efforts to establish mental, spiritual, emotional and physical balance.

Doctors continue to have a responsibility to report similar situations to child welfare authorities, says Jarvis. Those 
authorities should conduct sufficient investigation to satisfy themselves that families are pursuing a sincerely held practice of indigenous medicine, she adds. It's up to child welfare authorities, not doctors, to determine how sincerely held are the beliefs in traditional medicine, she cautions.

It was clear during the hearing that J.J's mother is a traditional Mohawk woman accessing indigenous medicines within the Six Nations community, Jarvis says. She calls media reports about the alternative treatment the family was pursuing at the Hippocrates Health Institute in Florida, "a red herring."
J.J.'s care in Florida was in addition to the traditional treatment she was getting on Six Nations, not instead of it, Jarvis says. Hill also visited the institute to help re-establish a connection to plantbased food, which is an important part of traditional healing.

Indigenous physicians can bridge the gap in understanding between the traditional and Western medical systems, says Hill. She hopes to help design a protocol for physicians about beginning that dialogue with patients and traditional healers.

Hill understands the angst both Makayla and J.J.'s cases have caused.
But she hopes the medical community will understand that Makayla's choice was about more than just medical treatment.

"It is about living and being Indigenous people, trusting our own medicines in the way we did for centuries before Western medicine. Behaving as indigenous people is what the mainstream finds difficult to understand and what the medical community needs to start working out in relationship with our people."- Laura Eggertson, Ottawa, Ont.

CMAJ 2015. DOI:10.1503/cmaj.109-4989 